\title{
SABORES E PAISAGENS DO JAPÃO: A EXPERIÊNCIA DO AGORA-AQUI EM JiRO TANIGUCHI
}

Pascoal Farinaccio*

Resumo: Propõe-se neste artigo a análise crítica de duas histórias em quadrinhos, Gourmet (2009) e O homem que passeia (2017), ambas de autoria de Jiro Taniguchi (com roteiro de Masayuki Qusumi em Gourmet). As obras são abordadas colocando-se como eixo central de interpretação a concepção nipônica de aproveitamento radical do tempo presente, conforme estudada e explicada por Shuichi Kato em seu livro Tempo e espaço na cultura japonesa (2012). Nessa linha de argumentação, que leva em conta a especificidade cultural japonesa, as histórias em quadrinhos de Jiro Taniguchi são aproximadas aqui, principalmente, dos procedimentos formais e do conteúdo semântico e espiritual do haikai.

Palavras-chave: Jiro Taniguchi. Histórias em quadrinhos. Haikai.

Apenas estando aqui, Estou aqui.

E a neve cai.

Kobayashi Issa

O historiador de literatura e acadêmico Shuichi Kato, em seu belo livro Tempo e espaço na cultura japonesa (2012), trata das concepções japonesas acerca das categorias de tempo e espaço enfatizando suas especificidades em relação à cultura ocidental. Para os objetivos deste ensaio, que tem como horizonte de análise as histórias em quadrinhos Gourmet (TANIGUCHI; QUSUMI, 2009) e O homem que passeia (TANIGUCHI, 2017), interessa-nos destacar da densa reflexão de Kato o que se refere ao aproveitamento radical do presente na experiência nipônica. A esse propósito, observa o autor: 
Em todos os niveis da sociedade japonesa, há uma forte tendência de se viver o presente, deixando o passado ser levado pelas águas e confiando o futuro à direção do vento. $O$ sentido dos acontecimentos do presente se define por si mesmo, independentemente da relação entre a história passada e a finalidade futura (KATO, 2012, p. 16).

Para Kato (2012), tal tendência japonesa de concentração no tempo presente, de vivenciá-lo em paz e plenitude, sem maiores preocupações com o passado e temores com o futuro, tem a ver com o componente filosófico e religioso do budismo, o que confere obviamente singularidade histórico-cultural a essa experiência conforme ali se apresenta.

A elaboração para ultrapassar e unir o tempo e o espaço dentro da cultura japonesa foi resultado do budismo importado do continente, em especial o misticismo do zen a partir do século XIII [...] o objetivo principal da iluminação, satori, é a superação da dualidade (como o eu e o outro; a subjetividade e a objetividade; um e muitos; a existência e o nada; o ser eterno e o nirvana; e a vida e a morte), e a superação da distância temporal é uma das faces dessa consciência (KATO, 2012, p. 25).

Kato (2012) procura elucidar a concepção temporal japonesa abordando diversas manifestações linguísticas, culturais e artísticas do país. Detenhamo-nos em duas que nos parecem não apenas esclarecedoras em si mesmas, mas também de grande rentabilidade para se pensar as obras referidas de Taniguchi: a pintura emakimono e, muito especialmente, a forma poética do haikai. Emakimono é uma pintura realizada sobre uma faixa de papel que é manuseada como os antigos pergaminhos, enrolando-se de um lado o que se desenrola de outro. Cada unidade dessa pintura em rolo tem coesão e sentido próprios, independentemente do conjunto total de cenas.

O emakimono é feito para ser apreciado cena a cena, ou seja, vê-se uma cena estendo-se uma parte do rolo, enrola-se o desenho que se acabou de ver e desenrola-se a próxima cena. Com a mão direita é enrolada a parte já vista, e com a esquerda vai se desenrolando a parte ainda não vista, e nenhuma delas pode ser apreciada junto com a cena que está diante da visão no momento. O presente está separado tanto do passado quanto do futuro [...] O tempo do emakimono é uma cadeia do presente que se enfileira de forma equivalente [...]. Cada cena é autoconclusiva, não afeta os acontecimentos anteriores e posteriores, e sua linha, coloração, ações da multidão, ambientes dos panoramas etc., apresentam-se por si mesmas [...] O emakimono não estrutura o tempo, destaca a natureza autoconclusiva do (mundo no) momento da conscientização. Aqui as pessoas vivem o presente (KATO, 2012, p. 120).

Vale enfatizar o caráter fechado e autoconclusivo das cenas do emakimono. Cada uma tem integridade e sentido próprios, que se constituem, conforme explicitado por Kato, independentemente dos efeitos do conjunto. E cada cena, nessa perspectiva, volta-se toda para o agora-aqui, a característica temporal a que o autor visa justamente esclarecer. Outra manifestação cultural japonesa afim à pintura emakimono (no que se refere à compreensão e apreensão do tempo com sua ênfase no momento presente) é o haikai, que é, como se sabe, uma forma poética brevíssima composta de três versos totalizando 17 sílabas, confor- 
me o esquema métrico 5-7-5. Citando palavras do grande escritor do período clássico da literatura japonesa, Matsuo Bashô (1644-1694), Kato (2012, p. 101) lembra que o haikai seria algo semelhante a "uma luz que se vê em algo, e deve ser fixada em palavras antes de se apagar do coração". É uma experiência poética que pressupõe "um tipo de sintonia entre o alvo da percepção (mundo exterior) e o întimo; surge num instante e se extingue no outro" (KATO, 2012, p. 101). Trata-se de forma literária que não se presta a cantar situações psicológicas duradouras como, por exemplo, o amor, mas sim a apreender a experiência sensivel do momento. A brevidade é a característica que faz aliança com a apreensão do presente: "A regra consiste no fato de que, quanto mais curta é a forma, mais o poema volta-se para o presente imediato" (KATO, 2012, p. 102).

Paulo Franchetti e Elza Taeko Doi são dois importantes pesquisadores, tradutores e divulgadores do haikai no Brasil. O livro Haikai: antologia e história (2012) apresenta uma densa introdução com diversas informações valiosas sobre a história e as características formais e temáticas do haikai. Nela, ficamos cientes de que para Bashô o haikai não se restringia a uma experiência literária formal, mas era entendida também, e essencialmente, como uma maneira de ver, compreender e situar-se no mundo:

A obra capital de Bashô foi a elevação do haikai ao estatuto de um michi, um dô, isto é, um caminho de vida, uma forma de ver e de viver o mundo. A partir do estabelecimento da Shômon, o haikai passa a ser um equivalente do Sadô caminho do chá -, enquanto forma iniciática de disciplina e exercício espiritual [...]. Os critérios estéticos japoneses, como é de esperar, possuem estreita ligação com o pensamento confucionista e budista, uma vez que o xintoísmo é mais uma forma de sentir e agir do que um corpo de doutrina de larga expressão intelectual (FRANCHETTI; DOI, 2012, p. 20-21).

$\mathrm{Na}$ relação do haikai com o mundo, vale dizer, do mundo íntimo do poeta com o mundo exterior, sobreleva uma valorização da coisa em si mesma. Da essência do pinheiro, deve-se aprender com o próprio pinheiro; do bambu, com o bambu - eis uma fórmula que constitui uma lição básica de Bashô. Há uma aderência do mundo íntimo à materialidade do mundo, uma conexão visceral, profunda, da intimidade psíquica com o mundo e suas infinitas coisas, sendo que cada parte em jogo ilumina e anima a outra.

[...] na maior parte dos textos de haikai, cada coisa é, primeiramente, não o símbolo de outra, mas ela própria e plena de sentido. E essa valorização da coisa em si mesma provém de duas origens: de um lado estão o amor pela natureza e o animismo tradicional japonês; de outro, a crença budista de que cada coisa está incessantemente pregando a Lei, de que a Lei é visível nas próprias coisas (FRANCHETTI; DOI, 2012, p. 39).

A valorização da coisa em si pressupõe uma atenção aguda, empática, respeitosa em relação à coisa contemplada. O haikai busca expressar a essência profunda de seu objeto com precisão, beleza e emoção poética sinceramente sentida (a categoria da "sinceridade" não é de importância como elemento de análise literária entre ocidentais, mas o caso é diverso no contexto nipônico, bastando lembrar aqui as palavras anteriormente citadas de Bashô acerca da necessidade de expressar em palavras aquilo que está vivo no próprio coração antes que desapareça). Por outro lado, vale destacar que tal valorização depende da capaci- 
dade de situar-se e sentir plenamente o agora-aqui. Como nos versos de Issa citados como epígrafe deste estudo, somente estando aqui (com todos os sentidos alertas para o entorno) está-se realmente aqui e com possibilidade de captar a essência do agora - no caso em questão, a neve que cai. Franchetti relembra uma anedota sobre Bashô que ilustra perfeitamente essa conexão profunda do haikai com o agora-aqui:

Diz a tradição que Bashô foi certa vez censurado por seu mestre zen, Bucchô, por desperdiçar tanto tempo com o haikai, em vez de se dedicar à meditação. A resposta de Bashô teria sido: "Haikai é simplesmente o que está acontecendo aqui, agora" - após o que teria dito o seguinte hokku:

As flores

Da beira da estrada O cavalo acaba de comê-las.

O comentário de Bucchô: "Muito bom! Muito bom! Então em haikai também há um sentido tão profundo?” (FRANCHETTI; DOI, 2012, p. 28).

Fizemos esses comentários preliminares sobre a vivência intensiva do presente na experiência nipônica (concretizada artisticamente pela pintura emakimono e pelo haikai, como visto, entre outros exemplos que também seriam possiveis referências, como o teatro nô e a dança) porque cremos que as histórias em quadrinhos Gourmet e $O$ homem que passeia, também podem ser aproximadas, com proveito para sua análise e interpretação, dessa singular experiência temporal. Como numa pintura emakimono, as duas histórias em quadrinhos apresentam cenas autoconclusivas, cujo sentido se define independentemente do conjunto: no caso de Gourmet, temos 18 capítulos, cada qual dedicado a uma refeição do protagonista em lugares diversos de Tóquio e arredores; em O homem que passeia, são igualmente 18 capítulos com o mesmo personagem, e em cada um deles é narrado um passeio por algum lugar diferente da cidade. As cenas desses capítulos têm começo, meio e fim, e não se vinculam em termos de causa e efeito com as demais: cada refeição e cada passeio começam e terminam no próprio capítulo, e o que vem a seguir é uma experiência completamente nova que começa, por assim dizer, do zero, e promete novas surpresas.

À parte o elemento formal pertinente ao caráter autoconclusivo das cenas, o que tem a ver, como demonstrado, com uma experiência de aproveitamento intenso do momento presente, há também uma grande sintonia dessas histórias em quadrinhos com o "espírito" do haikai. Mais uma vez, é preciso destacar o olhar atento ao que acontece no agora-aqui, como no gênero poético, mas também outras características de teor simbólico e existencial: o amor à natureza e aos pequenos eventos do cotidiano, a valorização da coisa em si, e, enfim, a sensibilidade muito atenta à materialidade do mundo, captada nos quadrinhos em paisagens, sabores, odores, que são recriados graficamente em imagens de forte impacto sensorial.

Passemos agora, portanto, aos quadrinhos, começando por Gourmet.

Das várias refeições do protagonista escolhemos a do Capítulo 9, intitulado "Enoshimadon em Enoshima, cidade de Fujisawa, província de Kanagawa", para nosso comentário. A escolha se dá porque consideramos que esta refeição, que inclui também um passeio por um lugar conhecido em tempos remotos pelo 
protagonista (nunca nomeado na narrativa) é de certa forma a mais "nostálgica", já que a personagem é tomada por lembranças de seu passado, em especial de uma relação amorosa que não foi adiante. Ainda assim, como se verá, o personagem não deixa de aproveitar o agora-aqui com todos os sentidos alertas e a boa disposição de sempre para degustar os pratos que lhe são servidos.

O capítulo se inicia com o personagem perambulando pelo Jardim Botânico de Enoshima; ocorrem-lhe antigas lembranças do lugar: a primeira vez que ali esteve, quando era um jovem estudante e tinha como companhia sua então namorada:

Figura 1 - Enoshima e as lembranças do passado

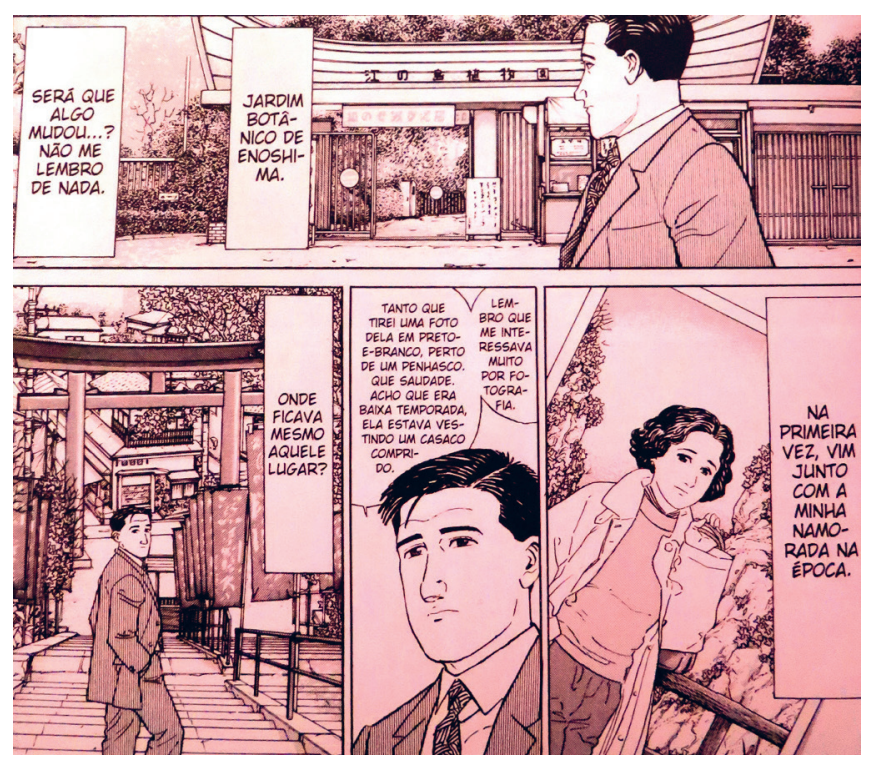

Fonte: Taniguchi e Qusumi (2009, p. 91).

O homem prossegue seu passeio sentindo uma leve melancolia ao lembrar-se desse amor perdido em passado remoto... Na sequência da caminhada encontra uma casa na qual se vende manju (doce japonês de feijão azuki), cuja existência já conhecia dos tempos de estudante. Sente-se feliz de reencontrá-la e pela oportunidade de provar novamente o doce que costumava comer:

Figura 2 - Provando novamente o manju
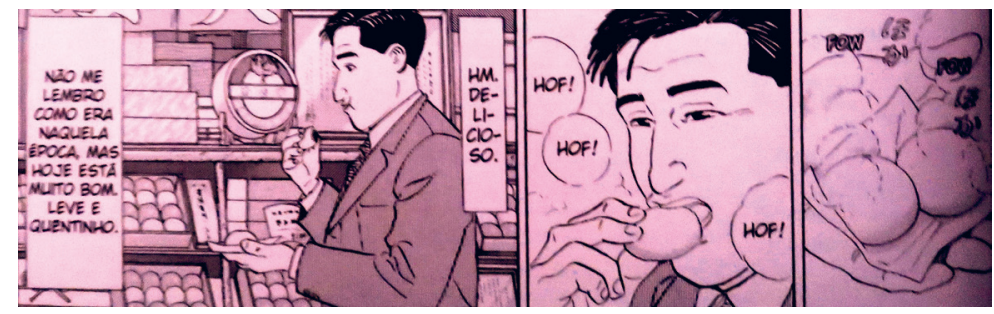

Fonte: Taniguchi e Qusumi (2009, p. 93). 
Esse episódio é um extraordinário exemplo de aproveitamento intenso do agora-aqui que temos sublinhado. A personagem não se lembra do sabor do doce dos tempos de outrora, mas percebe que hoje o manju é leve e quente, e é isso que afinal de contas lhe interessa. O manju, ao que tudo indica, produz um efeito inverso ao da famosa madeleine embebida no chá de Marcel Proust: na obra francesa o sabor faz emergir à tona um edifício imenso de recordações do passado, conferindo peso e medida à experiência de busca do "tempo perdido". Já na obra japonesa, o sabor presente do manju parece, ao contrário, bloquear o fluxo da memória, para detê-la em proveito das sensações que ocorrem agora-aqui, em larga medida desvinculadas de experiências vividas em tempos remotos.

Mais à frente o protagonista entra em um restaurante para a refeição principal:

Figura 3 - Momento da refeição

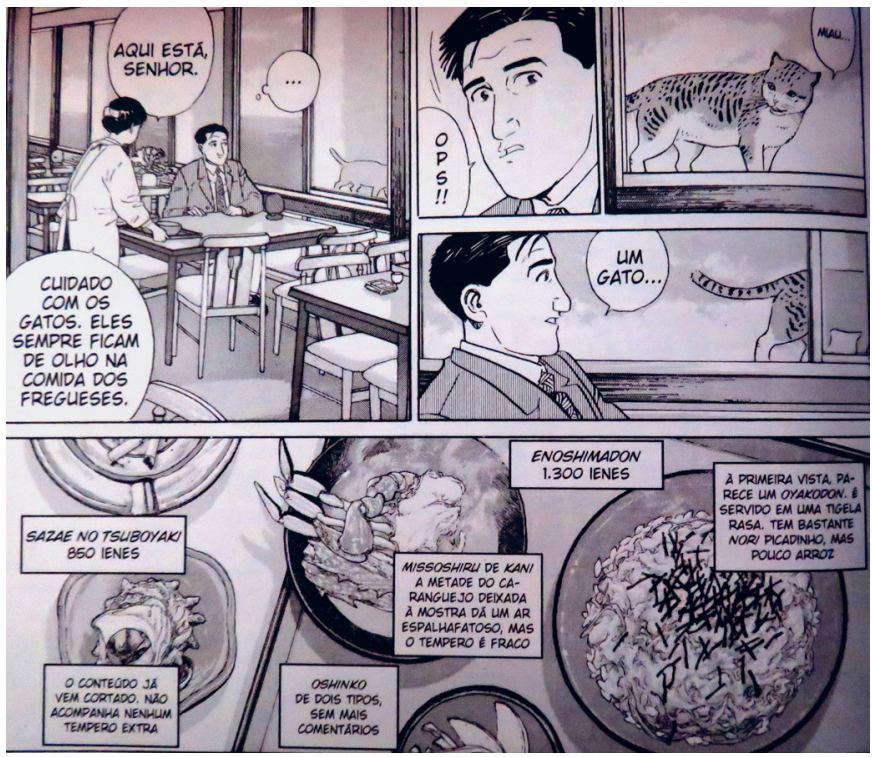

Fonte: Taniguchi e Qusumi (2009, p. 95).

Na Figura 3, temos a repetição, no que se refere à composição gráfica, de um procedimento formal que é reiterado em todos os capítulos: há um zoom nos pratos que serão comidos pelo protagonista com informações nos recordatórios (as caixas de texto inseridas nos quadros) acerca de preços dos alimentos preparados e dos sabores, condimentos, misturas, temperos etc. Segue-se invariavelmente a esse tipo de imagem em close uma série de observações bastante subjetivas do personagem sobre a qualidade dos pratos: se o que lhe oferecem agrada ou não ao seu paladar exigente. À parte seu caráter informativo, o foco que privilegia os alimentos, destacando-os, também favorece a noção temporal do agora-aqui: afinal, é preciso aproveitar o alimento antes que esfrie ou perca a consistência certa. Sem dúvida, a atenção do personagem também recebe solicitações de outros campos de informação - por exemplo, um gato que surge inesperadamente -, mas o ponto de concentração máxima reside sempre no prato de comida de nosso gourmet. Assim ocorre nos 18 capítulos que compõem a história. 
O próprio Taniguchi, no posfácio à obra, faz uma observação bastante interessante acerca do mundo moderno e suas implacáveis exigências de produtividade e desempenho, a aceleração temporal que marca os processos sociais contemporâneos e que trazem em seu bojo tantos desequilíbrios psiquicos: "O cotidiano frenético do mundo contemporâneo desequilibra o ser humano, que nada mais é que um sistema natural. Em outras palavras, o dia a dia agitado impõe um estado de desequilíbrio ao nosso corpo e mente" (TANIGUCHI; QUSUMI, 2009, p. 195). Taniguchi ressalta que o protagonista de Gourmet aprecia ficar sozinho, não permitindo que ninguém o atrapalhe ou distraia no simples (mas de forma alguma desimportante) ato de comer; dessa maneira, o homem foge - ainda que por um breve período de tempo - das opressivas "regras da sociedade" e das "amarras do tempo": "O feliz ato de saciar sua fome não seria uma forma de voltar ao estado primitivo do ser humano, curando-se da distorção de seu ser?" (TANIGUCHI; QUSUMI, 2009, p. 195).

Destaque-se o adjetivo empregado pelo quadrinista: feliz ato de saciar a fome. Trata-se, efetivamente, de uma felicidade, consubstanciada em um usufruto tranquilo do agora-aqui: usufruto lento, demorado o suficiente para que o prazer proporcionado pelos sentidos seja o mais pleno possivel. Em um belíssimo ensaio intitulado A alma precisa de tempo, Verena Kast (2016, p. 21) reflete sobre a "festa dos sentidos" que pode ser uma refeição bem aproveitada em tempo dilatado:

Nossas refeições poderiam ser uma festa para os nossos sentidos - mas muitas vezes não o são. Quando comemos correndo, com nossos pensamentos voltados para outra coisa, sem degustar a comida, perdemos algo. Uma existência sensorial seria enriquecedora - a vida aconteceria realmente onde estamos $e$ não onde não estamos. E são as pequenas alegrias que costumam aumentar a nossa qualidade de vida e que criam uma harmonia entre nós e o mundo.

O protagonista de Gourmet é bem esse ser dedicado à "existência sensorial" em cada refeição que faz; pode gostar ou não de determinado alimento, mas tudo é digerido com sentidos alertas, com atenção, com tempo necessário ou para usar aqui a expressão de Taniguchi - livre das "amarras do tempo", entendendo-se por isso a aceleração temporal tirânica da vida moderna.

É útil retomar, tendo chegado a esse ponto, algo mais sobre o haikai, do qual temos especialmente aproximado nossas histórias em quadrinhos. Como temos insistido, a personagem de Gourmet sabe aproveitar o agora-aqui, o momento presente. Em entrevista concedida a Casimiro de Brito, o poeta japonês contemporâneo Ban'ya Natsuishi, cuja atividade intelectual é dedicada tanto ao estudo e ao ensino como à produção autoral de haikais, explicita o aprendizado que alcançou com esse gênero poético para proveito de sua poesia e também de sua vida pessoal:

Essas pérolas, que tinham algo de lágrima, cortaram a ênfase da minha poesia, ensinaram-me a ver o mundo de uma forma fragmentária, a sentir melhor o aqui e o agora, e foi a partir desse acontecimento que a poesia me deu a concentração, o resumo que eu intuía, que o mundo é, em cada momento, um começo e um fim, que não há mais nada (BRITO, 2002, p. 92, grifo nosso).

Na história em quadrinhos O homem que passeia há um protagonista masculino não nomeado que faz diversas caminhadas por sua cidade. Em cada uma 
delas a personagem acaba fazendo descobertas inéditas, cada qual com sua graça, beleza e encanto que enchem sua alma de prazer: uma árvore na qual decide subir, a surpresa da chuva ou da neve que caem de repente, um parque até então desconhecido, uma noite especialmente estrelada, uma viela que se percorre de olho nos afazeres cotidianos dos moradores... Cada uma dessas caminhadas é autossuficiente, isto é, seu sentido completa-se na própria caminhada em pauta, independentemente das outras. As caminhadas são um começo e um fim, precisamente.

Jiro Taniguchi, em entrevista cedida ao escritor Jean-Phillipe Toussaint e intitulada "A caminhada como liberdade", a qual faz parte do volume O homem que passeia, esclarece a propósito de sua concepção de caminhada:

O que tenho é a sensação de que, dentre as ações cotidianas dos seres humanos, a caminhada é a mais natural. E é também, creio eu, uma atividade especialmente importante, sobretudo quando não tem nenhum objetivo preciso. Para mim, o passeio deve ser uma liberdade. Nem objetivo nem limites de tempo devem obstrui-la [...]. Quando caminhamos devagar, podemos descobrir coisas fugidias. São, claro, coisas infimas, acontecimentos pequenos que nos enriquecem $e$, se me deixar levar por meu entusiasmo, diria até que às vezes nos deparamos com coisas que nos fazem sentir plenamente o prazer da vida. Podemos experimentar sentimentos novos com a visão das plantas ou das pedras ao longo do caminho. O passeio possibilita sensações novas, sentimentos novos (TANIGUCHI, 2017, p. 235).

Mais uma vez, Taniguchi coloca em destaque - como também o fez em Gourmet - o exercício de uma atividade que se desenrola dentro de um tempo próprio, muito diferente daquele exigido pelo time is money do atual momento do capitalismo. Caminha-se devagar, sem que "limites de tempo" possam obstruir a trajetória que se cumpre sem objetivos predeterminados. Caminha-se não para se chegar a algum lugar preciso, caminha-se pelo simples prazer de caminhar... Como não há ponto de chegada específico, o interesse reside justamente no próprio movimento, em um deslocar-se que é pleno de gratuidade. Uma verdadeira arte de caminhar: uma finalidade sem fim. O tempo dilatado condensa a experiência mediante seu enriquecimento pelas descobertas das "coisas fugidias", das coisas pequenas, mas de forma alguma insignificantes, que fazem com que as pessoas sintam o prazer de estarem vivas.

Para fins de nosso comentário, dentre as 18 caminhadas do protagonista, escolhemos a narrada no oitavo capítulo, intitulado "Margeando o rio". Ela se inicia justamente com um pensamento do personagem: "Nesse dia, sem qualquer motivo... desci uma estação antes daquela em que fica o escritório" (TANIGUCHI, 2017, p. 79). Estamos aqui em plena caminhada conforme a concebe o autor: o passeio inicia-se desvinculado de qualquer objetivo racional - "sem qualquer motivo... desci uma estação antes..." (TANIGUCHI, 2017, p. 79) - e o que segue são pequenas descobertas que enchem a alma do personagem do mais puro prazer sensorial. É um belo dia de primavera, o tempo está muito bom, o que inspira a caminhada e sentimentos e emoções de liberdade: "Nos sentimos livres sem ter motivo nenhum" (TANIGUCHI, 2017, p. 80). O passeio prossegue: acompanhamos o homem, que aqui sente o perfume bom de uma magnólia, acolá se depara com um gato preguiçosamente deitado em uma janela. A sensação de uma nova qualidade de tempo se impõe: "Era tão silencioso... 
como se o tempo tivesse parado" (TANIGUCHI, 2017, p. 82). Por fim, ele sai da avenida convencional e toma uma viela; depara-se então com um rio espaçoso e decide continuar a caminhada margeando-o. Pelo caminho encontra um senhor que está pescando:

Figura 4 - O encontro com o pescador

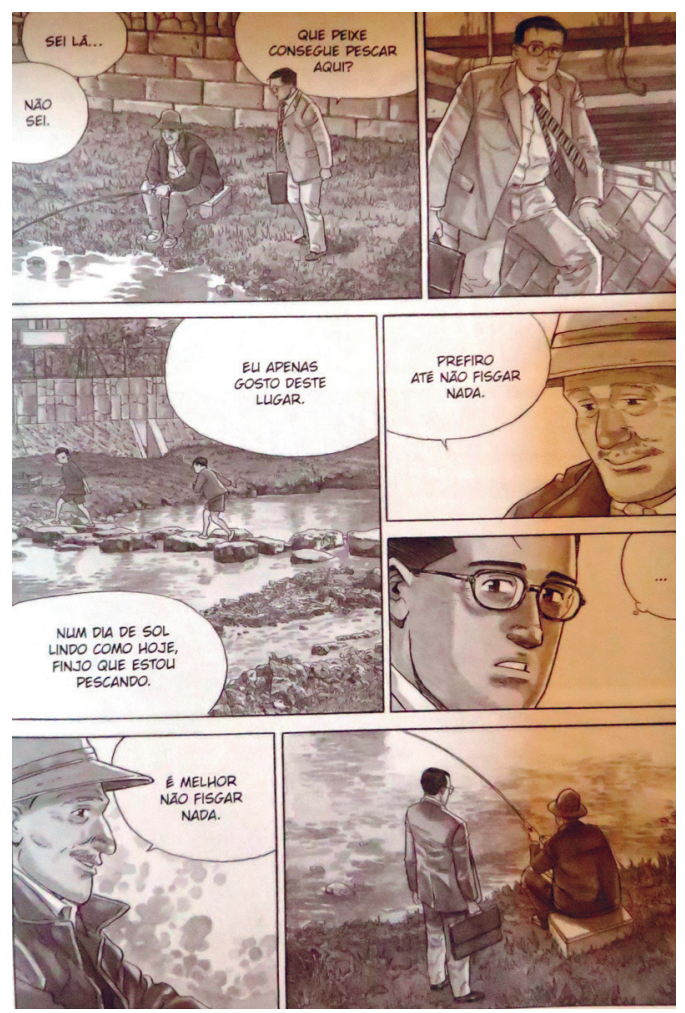

Fonte: Taniguchi (2017, p. 86).

A cena é extraordinária, pois sintetiza na fala do pescador o que há de essencial na visão tanuguchiana de caminhada, a qual se desdobra graficamente, com as devidas variações de cenários e personagens, nos diferentes capítulos. $\mathrm{O}$ pescador diz que pesca sem a pretensão de fisgar qualquer peixe... O belo dia de sol o leva a "fingir" que está pescando, sendo que, na verdade, seu interesse reside em tão-somente desfrutar o dia de forma prazerosa - gosta do lugar, por isso está ali... Não há objetivo senão aquele de viver a vida, de senti-la em plenitude, enfim.

Na Figura 5, mais uma vez, nota-se que a personagem tem a sensação de um tempo dilatado: "aqui o tempo anda mais devagar". Evidentemente, trata-se de uma diferença qualitativa na experiência do tempo: não se trata aqui do tempo dos relógios, do ritmo frenético que muitas vezes agride o tempo subjetivo, individual, próprio de cada pessoa, causando, muitas vezes, nesse choque entre o ritmo externo e o interno, esgotamento psíquico e depressão - doenças de grande vigência na atualidade. 
Figura 5 - O tempo que passa lentamente
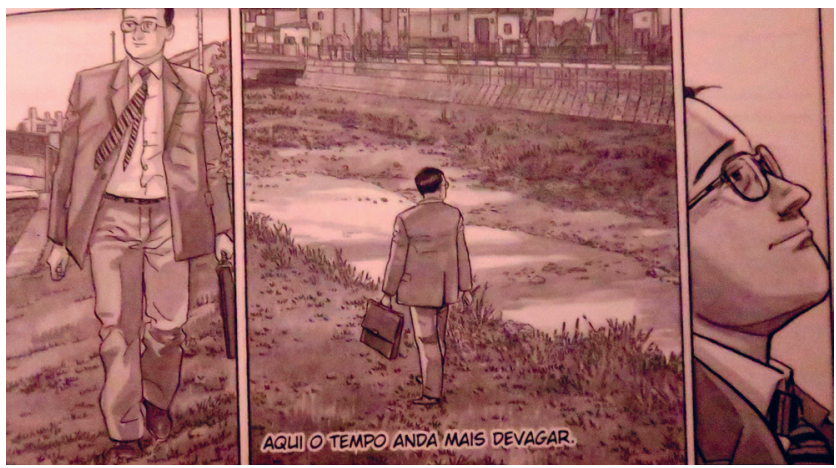

Fonte: Taniguchi (2017, p. 88).

$\mathrm{Na}$ ilustração seguinte, que marca o final do capítulo, o homem vai concluindo sua caminhada. Mas o faz mantendo a mesma atitude tomada desde o princípio: move-o o desejo de enveredar por caminhos novos e desfrutar as pequenas descobertas feitas no trajeto até então desconhecido. Sem a necessidade de apressar-se, um caminhar, pois, que faz da calma um ingrediente indispensável à experiência do passeio. Tempo dilatado, calma: aspectos essenciais que permitem que as coisas vistas falem à alma, sedimentem-se e enriqueçam a vida psicológica - podendo inclusive serem posteriormente retomadas pela memória afetiva, já que certamente se depositam como vivências prazerosas da experiência deste "homem que passeia".

Figura 6 - O caminhante sem pressa

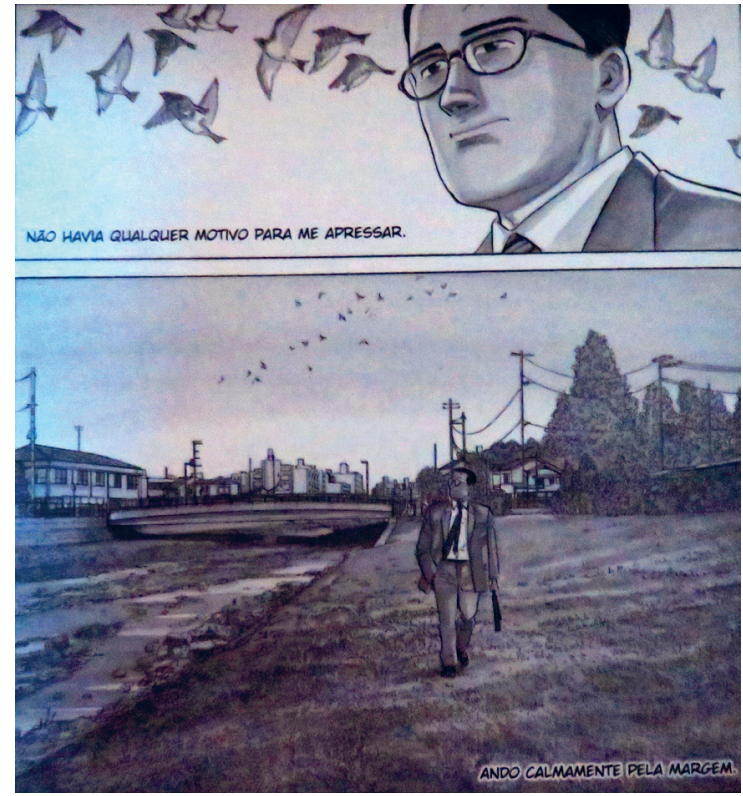

Fonte: Taniguchi (2017, p. 89). 
O filósofo e psicólogo junguiano James Hillman escreveu um comovente ensaio no qual recorda um passeio que fez em um jardim em Kioto. O passeio o leva a refletir sobre as características singulares de um jardim japonês:

[...] o jardim japonês não oferece uma posição central na qual se possa estar e da qual se possa vê-lo todo. Só se pode fazer um exame de uma parte a cada vez. Cada ponto de observação é limitado: não há uma visão global que abrace tudo. Ao invés de panorâmica e totalidade, há perspectiva e singularidade. $O$ mundo muda à medida que nos movemos (HILLMAN, 1999, p. 149).

O jardim japonês obriga então o caminhante a rever seus vários elementos (flores, árvores, fontes, águas que escorrem entre pedras, folhagens, pontes) sempre de uma diferente perspectiva. Esse rever, esse ver de novo, é uma ação que condiz com a essência daquilo que se pode chamar de respeito:

Estes mutamentos do re-ver, da segunda visão, são propriamente aquilo que indicam as palauras "atenção", "respeito". Re-speitar significa olhar de novo. Cada vez que olhamos a mesma coisa de novo adquirimos maior respeito em seus confrontos e aumentamos sua respeitabilidade (HILLMAN, 1999, p. 149).

Quando lemos um haikai notamos o profundo respeito do poeta pela paisagem que contempla e representa em palavras. É também esse respeito, nesse sentido profundo indicado por Hillman, que prima pelo rever as coisas e assim aumentar sua respeitabilidade no agora-aqui da percepção - tal respeito nós também o identificamos nos quadrinhos de Jiro Taniguchi.

\section{Flavors and landscapes of JaPAN: THE NOW-HERE EXPERIENCE IN JiRo TANiguchi}

Abstract: This article proposes the critical analysis of two comic books, Gourmet (2009), by Jiro Taniguchi with screenplay by Masayuki Qusumi and The walking man (2017), by Jiro Taniguchi. The works are approached by placing as a central axis of interpretation the nipponic conception of radical use of the present time, as studied and explained by Shuichi Kato in his book Time and space in Japanese culture (2012). In this line of argument, which takes into account Japanese cultural specificity, Jiro Taniguchi's comic books are mainly approximated by formal procedures and the semantic and spiritual content of haikai.

Keywords: Jiro Taniguchi. Comics. Haikai.

\section{REFERÊNCIAS}

BRITO, C. Divan Ocidental-Oriental. Poesia sempre. Revista Semestral de Poesia, Rio de Janeiro, ano 10, n. 17, dez. 2002.

FRANCHETTI, P.; DOI, E. T. Haikai: antologia e história. Introdução, notas e textos críticos por Paulo Franchetti; seleção e tradução dos haikais por Elza Taeko Doi e Paulo Franchetti. 4. ed. rev. Campinas: Editora da Unicamp, 2012. KAST, V. A alma precisa de tempo. Tradução Markus A. Hediger. Petrópolis: Vozes, 2016. 
KATO, S. Tempo e espaço na cultura japonesa. Tradução Neide Nagae e Fernando Chamas. São Paulo: Estação Liberdade, 2012.

TANIGUCHI, J. O homem que passeia. Tradução Arnaldo Oka. São Paulo: Devir, 2017.

TANIGUCHI, J.; QUSUMI, M. Gourmet. Tradução Drik Sada. São Paulo: Conrad Editora do Brasil, 2009t.

HILLMAN, J. Nei Giardini: un ricordo psicologico. In: HILLMAN, J. Politica della Bellezza. Tradução Paola Donfrancesco. Bergamo: Moretti \& Vitali, 1999.

Recebido em 9 de novembro de 2018. Aprovado em 23 de março de 2019. 